\title{
La India en los BRICS: una nueva forma de promover sus intereses en el escenario internacional
}

\author{
Jacobo Silva ParadA*
}

\section{RESUMEN}

En los últimos veintitrés años, India ha cobrado mayor notoriedad debido a su acelerado crecimiento económico -sólo eclipsado por el de China-y a una nueva política exterior que se calificaría como pragmática. La forma en que Nueva Delhi se desenvuelve en el escenario internacional es una consecuencia natural de lo anterior. Así, los BRICs son parte de una estrategia más amplia para la proyección de sus intereses políticos y económicos en diversos foros y organizaciones internacionales, lo que le permite, de forma flexible y sin compromisos, adaptarse y enfrentar los nuevos cambios y retos del siglo XXI.

Palabras clave: India, BRICS, ONU, seguridad, comercio, China.

\section{AbStRACt}

Over the last 23 years, India has become more noteworthy due to its accelerated economic growth, eclipsed only by China, and a new foreign policy that can be classified as pragmatic. The way New Delhi behaves on the international stage is a natural consequence of this. So, the BRICS are part of a broader strategy to project its political and economic interests in different international forums and organizations. This allows it to flexibly and non-committally adapt and deal with the twenty-first century's changes and new challenges.

Key words: India, BRICS, un, security, trade, China.

\footnotetext{
* Miembro del Centro de Análisis e Investigación sobre Paz, Seguridad y Desarrollo, Olof Palme A. C., yamatoc@yahoo.com
} 
Durante los últimos veinte años, el sistema internacional ha sufrido una serie de cambios importantes. De acuerdo con Fareed Rafiq Zakaria, se experimenta la continuación de dos etapas o transformaciones en la distribución de poder del sistema internacional, cambios que han reconfigurado la vida internacional, tanto en la política y la economía, como en la cultura. La primera etapa se caracteriza por el auge en la economía, la política, la ciencia y la cultura del mundo occidental desde el siglo xv y la aceleración de su dominio durante el siglo xviII. La segunda etapa consiste en el ascenso de Estados Unidos como la nación más poderosa desde finales del siglo XIX, cuyo dominio en política, economía, ciencia y cultura no tuvo rival. La tercera y actual transformación se caracteriza por "el auge de los demás", es decir, de otros polos o centros de poder que, si bien no desafían el dominio militar estadunidense, sí hacen patente su desacuerdo respecto de la influencia de éste en lo económico y político (Zakaria, 2011: 1-2).

En otras palabras, se transitaría a lo que el académico indoamericano define como un mundo posestadunidense - distinto de uno antiestadunidense- a raíz de los cambios en la política y economía internacionales, lo cual se traduce en una alteración de la distribución de poder en el mundo. Un escenario en el que Washington no deja de perder su influencia militar a escala global, pero donde nuevos actores estatales se consolidan y cuestionan la omnipresencia estadunidense en la economía y política internacionales, sin mencionar el ascenso de las organizaciones no gubernamentales (ONG) y las organizaciones internacionales gubernamentales (OIG), las cuales también demandan un espacio importante en el escenario internacional, aunque estas últimas no han sabido adaptarse del todo a los cambios del sistema internacional (Zakaria, 2011: 6-37).

Así, algunos ejemplos de estos actores son China e India, cuyo crecimiento económico es el más dinámico del orbe, o de tipo no estatal, como algunas ONG, grandes transnacionales o los grupos terroristas, insurgentes o cárteles de narcotraficantes -lo cual también evidenciaría un cambio en la distribución de poder que iría alejándose de los Estados-nación-. En el plano político, Rusia y China tienen una actitud mucho más asertiva frente a Estados Unidos en el Consejo de Seguridad de la Organización de las Naciones Unidas (ONU), como muestran las votaciones de los últimos once años en este órgano, entre otros de la misma organización. Lo cual no señalaría de forma contundente que Estados Unidos experimenta una etapa de decadencia, sino más bien que está pasando por una adaptación a los nuevos cambios que impone el sistema internacional. No obstante, si dicha adaptación es positiva o negativa, es muy prematuro de señalar. Baste decir que las conclusiones precipitadas de los defensores, en los años setenta y ochenta, de la teoría de la estabilidad del hegemón, siguen sin sustento. 
Sería más acertado establecer que la nueva dinámica en el sistema internacional que imponen las estructuras financiera, militar, de seguridad y del conocimiento también provoca desequilibrios, perturbaciones y cambios en Estados Unidos, así como en los demás países. De esta forma, el desmembramiento de la Unión de Repúblicas Socialistas Soviéticas (URSS), las constantes crisis económicas y financieras, los cambios en la estructura de la economía mundial (Wade, 2003: 621-633; Weiss, 2005: 723-730, 744-745) y la transición del carácter interestatal al intraestatal de los conflictos de finales del siglo xx y principios del xxI, entre otros factores, resultan en que la hegemonía de Estados Unidos tenga que adaptarse a estos nuevos tiempos en los que aparecen nuevos centros de poder.

En los casos de las economías del grupo del BRics (Brasil, Rusia, India, China y Sudáfrica $)^{1}$ las cosas no son tan diferentes, ya que si bien se tiene la impresión de que influyen significativamente en ciertos mercados, como el de los energéticos, los alimentos, los servicios y el financiero, desde la perspectiva de la oferta y la demanda, y que la distribución de poder en el sistema internacional parece serles más favorable que a Estados Unidos, dichas economías todavía se muestran tendientes a no desafiar directamente a las instituciones creadas después de la segunda guerra mundial: el Banco Mundial (BM), el Fondo Monetario Internacional (FMI), la Organización Mundial del Comercio (OMC) -heredera del Acuerdo General de Aranceles Aduaneros y Comercio (GATT, por sus siglas en inglés)-, no obstante que cada vez parecen defender más férrea y coordinadamente sus posiciones en los distintos foros multilaterales, de cierta manera, proporcionalmente al peso económico y político que adquieren en la estructura del sistema internacional y, en algunos casos, en el militar. De acuerdo con Zakaria, diez años antes, nadie podría haber advertido que estos países empezarían a tener una actitud más asertiva frente a las posiciones de Estados Unidos en los distintos foros citados, ni que su potencial económico devendría en una especie de potencial político (Zakaria, 2011: 2-5).

\section{INDIA Y LA TRANSFORMACIÓN DEL SISTEMA INTERNACIONAL}

En el caso particular de India, las cosas van mucho más allá, al reclamar incluso un papel más activo y con una correspondiente mayor responsabilidad en la escena internacional, concretamente en el Consejo de Seguridad de la ONU. Si bien este activismo siempre ha caracterizado a la diplomacia india, también es cierto que después de

\footnotetext{
${ }^{1}$ Antes del 14 de abril de 2011, eran cuatro: Brasil, Rusia, India y China, y se conocían como el BRIC. A lo largo de este trabajo se usará las siglas BRICs, a menos que se haga una referencia histórica a aquél.
} 
1991 y su crisis de la deuda Nueva Delhi reconfiguró los pilares de su diplomacia, adaptándose a la nueva realidad nacida de la caída del muro de Berlín. Así, el no alineamiento se abandonó en el discurso y la acción, al ser remplazado por un cierto pragmatismo político. La cooperación internacional tomará una nueva dimensión y una especie de diplomacia económica o política comercial externa tomará mayor definición (Ganguly, 2003: 93-97; Mathews, 2011: 40-46).

En otras palabras, a la par de irse adquiriendo nuevas capacidades e incrementando otras, India empezará a adaptarse a los cambios en el sistema internacional, algunas veces de forma titubeante, pero obteniendo buenos réditos en lo general. Al grado de ser vista como un interesante nicho de inversión y, por ende, miembro del grupo del BRIC.

Al respecto, hay opiniones como las de María Cristina Rosas, quien califica a este grupo como una especie de club que busca más bien hacerse de una visibilidad en la esfera internacional, especialmente frente a los inversionista extranjeros, cuyos capitales son importantes para financiar proyectos y empresas en su territorio (Rosas, 2011), lo cual tal vez no esté fuera de la realidad, teniendo en cuenta que varios de los materiales publicados sobre el BRICs los elaboran analistas financieros que explican las ventajas y desventajas de invertir en estos países.

Sin embargo, si bien el BRICs es un grupo bastante informal, también es cierto que es un buen foro para mantener el contacto bilateral y trilateral entre estos países, al mismo tiempo que les da una importante publicidad frente a los reflectores de los medios informativos mundiales. Esto les permite evidenciar sus intereses en ciertas áreas de la economía y la política mundiales, además de defenderlos en esos medios y en diferentes escenarios. Tal es el caso de las negociaciones comerciales de la Ronda de Doha en la OMc o las de tipo ambiental en las Conferencias de las Partes (COP15) ${ }^{2}$ y сор16, sin olvidar ciertas similitudes en su actitud frente a conflictos relativamente nuevos, como el de Afganistán e Irak o el de Egipto o Libia.

En ese contexto, India se ve inmersa en un entorno bastante complejo. En el plano económico, si bien es el país con el segundo crecimiento más dinámico del mundo, también es una economía con un desarrollo humano mediano, localizándose entre Cabo Verde y Timor Oriental en 2009, de acuerdo con el Programa de Naciones Unidas para el Desarrollo (PNUD). En otras palabras, es un gigante económico, pero también un país donde la desigualdad en el ingreso de sus habitantes es muy elevada, sin mencionar que sus zonas rurales pasan por una importante pauperización, que también llega a los grandes centros urbanos.

\footnotetext{
${ }^{2}$ El cop es el órgano de gobierno de la Convención Marco sobre Cambio Climático de la onu cuyo objetivo es crear instrumentos jurídicos internacionales para tratar el problema del cambio climático, a través de la estabilización de las concentraciones de gases de efecto invernadero (GEI).
} 
Pese a ello, su economía parece estar llena de ciertas potencialidades, sin mencionar que la apertura económica gradual que experimenta desde los años noventa le ha permitido desenvolverse de forma exitosa en ciertos sectores en el plano internacional. Tal vez porque más allá de centrar su crecimiento económico en el sector agrícola o industrial, lo ha hecho en el sector terciario, de servicios, el cual desafortunadamente no emplea a un número tan elevado de personas como los dos primeros. No obstante que hay importantes adelantos en el desarrollo de los primeros dos sectores (Boillot, 2009: 37-38).

Sin embargo, esto no le ha impedido desarrollar una muy articulada política comercial externa que se extiende desde su vecindad más próxima en Asia del Sur, hasta regiones más alejadas como Asia del Este o el Sudeste Asiático, pasando por Medio Oriente y África: las llamadas políticas del Look East y Look West, las cuales buscan mantener el abastecimiento de materias primas para la economía india en su conjunto, así como el acceso a diversos mercados para sus productos y servicios, debido a que el crecimiento económico indio depende en gran medida de ello.

De la misma manera, el entorno político se vuelve hasta cierto punto idóneo para mejorar su posición en la escena internacional. En el entendido de que las mismas relaciones con los demás países del BRIcs se han estrechado y mejorado. Especial atención merecen los acercamientos con el régimen chino, los cuales han abierto la posibilidad para una regularización plena de las relaciones entre ambos gigantes demográficos, como lo muestran las múltiples visitas mutuas de líderes de ambos países (PTI, 2010a; 2010b; ITGD Bureau, 2011a). La trascendencia de esto deviene de las desavenencias durante la segunda mitad del siglo xx, como el caso de la guerra de 1962-1963, cuyo resultado fue la derrota de India y la anexión por parte de Pekín de la región de Aksai Chin, parte de Cachemira india. Esta conflagración dejó a Nueva Delhi con un sentimiento de humillación y desprotección, que se intentará contrarrestar a través de una alianza indo-soviética. Asimismo, hay otros puntos fronterizos en disputa, como el de Arunchal Pradesh, que está en manos de India y es reclamado por China, lo cual también impulsó una alianza sino-paquistaní frente a Nueva Delhi.

Pese a lo anterior, y como prueba de que hay perspectivas de cambio, por un lado, en 1988, el premier indio Rajiv Gandhi visitó Pekín e inició un proceso de normalización de las relaciones sino-indias que continuarán los premieres Narasimha Rao y A.B. Vajpayee; por el otro, a pesar de sus lazos de cooperación militar desde 1996, China se ha negado a apoyar a Pakistán en su reclamo por Cachemira, lo que también ha ayudado a relajar el ambiente. Todos estos esfuerzos culminaron en 2005, cuando el premier chino Wen Jibao, de visita en India, firmó una alianza estratégica por la paz y la prosperidad, encuentro en el que Nueva Delhi reconoció la pertenencia del territorio autónomo del Tíbet a la República Popular y ésta admi- 
tió que el Sikkim, territorio fronterizo, es un estado de la unión india (Sur, 2005: 25 y 62 ).

Ese mismo año ocurrieron dos hechos clave: en primer lugar, India, Pakistán e Irán fueron admitidos como observadores en la Organización para la Cooperación de Shanghai, ente impulsado por China que ha presentado una posición crítica frente a la presencia estadunidense en Asia Central y de las fuerzas internacionales en Afganistán que usan bases militares en esta región; en segundo lugar, China, sin Hong Kong, se vuelve por primera vez el principal importador de bienes indios en Asia y el tercero en el mundo -el 10 por ciento de las mercancías indias-, mientras que China se vuelve el principal origen de las importaciones indianas, dejando atrás a Estados Unidos. No obstante esto, hay todavía reticencias por parte de Pekín de emprender proyectos energéticos de más amplia envergadura como un gasoducto Irán-Pakistán-India-Myanmar-China (Sur, 2005: 25 y 63). De la misma manera, en este año también India y Estados Unidos firman un acuerdo de cooperación nuclear para fines pacíficos, lo cual deja ver que Nueva Delhi busca establecer y equilibrar sus relaciones político-económicas y no dejar fuera del todo a la Estados Unidos.

Pese a lo anterior, sigue habiendo malentendidos y tensiones, como ocurrió en julio de 2010 al haberse negado Pekín a dar una visa al teniente general B.S. Jaswal para visitar territorio chino, el cual era en ese momento comandante de la Armada del Norte, quien sirvió en la provincia de Jammu y Cachemira, en disputa con Pakistán, aún aliado de China. Dicho mando iba a una de varias reuniones de alto nivel sobre defensa y este altercado las suspendió durante nueve meses (India Today, 2011a; Joshi, 2011).

En el caso de la región de Asia del Sur, India ha establecido acercamientos y mecanismos de cooperación -como el Programa Indio de Cooperación Económica y Técnica (ITEC, por sus siglas en inglés)-, con sus vecinos: Bután, Bangladesh, Nepal, Sri Lanka, las Islas Maldivas y Myanmar, lo cual ha ayudado a mejorar el entendimiento con ellos y a estrechar las relaciones, como lo muestra la creación en 1985 de la Asociación de Asia del Sur para la Cooperación Regional (SAARC, por sus siglas en inglés). ${ }^{3}$ Sin embargo, el caso que más inquieta a Nueva Delhi por su propincuidad y nivel de violencia es el de Pakistán, país con el que ha tenido diversas diferencias y contiendas bélicas debido a conflictos fronterizos y de control del territorio de la provincia de Cachemira.

No obstante, en los últimos años se han dado progresos vacilantes con el objetivo de normalizar las relaciones con Islamabad, además del establecimiento de un mecanismo de negociación para dar salida a este conflicto regional (ITGD, 2011b). De

\footnotetext{
${ }^{3}$ Pakistán es miembro, al igual que Afganistán, que entró en 2005; mientras que Australia, China, Myanmar, Unión Europea, Japón, Irán, Islas Mauricio, Corea del Sur y Estados Unidos tienen el estatus de observadores.
} 
singular importancia es la delicada situación del país musulmán después de la guerra en Afganistán, además de las revueltas y conflictos internos, ya sea de naturaleza ambiental, económica o política; sin mencionar que los presuntos vínculos entre los servicios de inteligencia paquistaníes, el Directorate for Inter-Services Intelligence (ISI) y los grupos terroristas islamistas indios son evocados en los medios cada vez que hay un atentado en territorio indio, como el acontecido en julio de 2011 en Mumbai. En esencia, la question pakistanaise sigue siendo un tema muy importante en la relación bilateral entre Islamabad y Nueva Delhi, pero además en la agenda interna y externa del subcontinente.

En el caso de Rusia, los antecedentes se remontan a la alianza tejida con la URSS, pese a la posición oficial india de no alineamiento. Dicha asociación fue de tipo político-militar, cuyos frutos se aprecian hoy en día en los mecanismos de cooperación en la producción de misiles. Si bien esta alianza fue bastante sólida en lo político, en lo económico fue bastante débil, ya que el comercio en su mayoría se limitó a pertrechos militares. Asimismo, en esta relación hubo tensiones, por un lado, el distanciamiento entre China Popular y el bloque soviético en los años setenta hizo que India apreciara a Moscú como un aliado que podría ayudarla a contener a Pekín y, por ende, a Pakistán, en lo militar; por el otro, la incursión militar soviética de 1979 en Afganistán fue un factor muy importante de presión para India, debido a que Estados Unidos intervino en dicha conflagración a través de su apoyo militar a Pakistán, rival de India. Es cierto que dicha guerra no puso en peligro las relaciones indo-soviéticas, sin embargo, sí impuso retos a Nueva Delhi al grado de obligarla a dar su consentimiento tácito a la empresa militar soviética, mermando su imagen de país no alineado, y a distanciarse de Estados Unidos, con la consecuente dependencia político-militar hacia la URSS (Ganguly y Pardesi, 2009: 10).

Cuando se da el desmembramiento soviético, Rusia es la heredera del mayor peso de la relación con India y debido a los periplos por los que pasa la economía y política rusa se experimenta un enfriamiento en los contactos indo-rusos, aunque éstos nunca se degradaron completamente en el seno de la cooperación militar, pese a lo cual Israel pasó a ser un importante proveedor de armamento. Durante la primera década del siglo xxI, la situación de Rusia cambia y se puede ver un nuevo auge en su economía, así se va incrementando la relación en defensa, con nuevas compras militares -no obstante la conveniencia de otros proveedores (Dikshit, 2008)-, y el desarrollo de los misiles supersónicos. Y si bien en el aspecto comercial la situación no ha mejorado, hay contactos políticos frecuentes y en el marco de los BRICs se ha relanzado la relación, como lo muestra el hecho de que en 2009, durante la primera reunión del BRIC, en Ekaterimburgo, Rusia, fue declarado año de India en Rusia, con un importante despliegue de encuentros culturales y académicos. Asimismo, en 2013, 
los países han acordado la formación de un grupo de trabajo conjunto para evaluar la posibilidad de firmar un Acuerdo de Cooperación Económica Amplia entre India y la Unión Aduanera de Rusia, Kazajastán y Bielorrusia, que dejaría fuera el rubro de las inversiones. Este acuerdo sería una herramienta para disminuir la dependencia comercial de India frente a Estados Unidos y la Unión Europea (Sen, 2013).

Los casos de Brasil y Sudáfrica muestran también un acercamiento progresivo que ha culminado en el diálogo trilateral IBS (India, Brasil, Sudáfrica), establecido en 2003 y que hasta la fecha mantiene su estructura. De hecho, este foro ofrece una mayor comodidad a India, ya que es el país con las tasas de crecimiento más elevadas, aunque Brasil es la economía más grande. Igualmente, no se puede perder de vista que los tres países buscan un asiento permanente en el Consejo de Seguridad de la ONU, por lo que se han unido y coordinado en sus intentos por conseguirlo. Otro aspecto a considerar es que ambos países se aprecian como las entradas de los productos y servicios indios a los mercados latinoamericano y africano, al igual que al acceso a ciertas oportunidades de negocio para las iniciativas privada y pública indias. ${ }^{4}$

\section{LA INDIA Y LOS BRICS, UNA BREVE HISTORIA}

Habiendo establecido el contexto regional y global en el que India se desenvuelve, es importante explicar cómo los BRICS son una herramienta para desahogar ciertas agendas, coordinar algunas posturas en foros internacionales, mantener y consolidar relaciones, y con ello establecer una proyección internacional que, por un lado, la hace ver como un líder en la arena internacional y por el otro la promueve en el mercado financiero internacional.

Así, BRICs nacen como concepto en el año 2001, a través del banco de inversiones Goldman Sachs, en su informe de la economía global núm. 66 "The World Needs Better Economic BRICs", de Jim O'Neill. Dicho informe forma parte de la realización de un modelo económico para pronosticar las tendencias de la economía global en los siguientes cincuenta años.

Sin embargo, el establecimiento más formal, de BRIC se da el 16 de junio de 2009 en la cumbre de Ekaterimburgo, Rusia, donde se reunieron los líderes políticos más importantes de cada país, cuyo resultado fue una declaración conjunta sobre seguridad alimentaria global. No obstante, es preciso mencionar que el BRIC tuvo contactos previos a través de otros funcionarios en fechas anteriores. Tal es el caso de las reuniones

\footnotetext{
${ }^{4}$ Después de que finalizó el régimen del apartheid, India inició un importante acercamiento diplomático con Pretoria, el cual culminó una de sus etapas con la entrada, en 2011, del país africano al BRICs.
} 
frecuentes de sus correspondientes ministros de relaciones exteriores en el seno de la Asamblea General de la ONU en 2006, o las reuniones autónomas entre los mismos funcionarios en mayo de 2008, realizadas igualmente en Ekaterimburgo. Asimismo, los ministros de finanzas y economía de los países del BRIC tuvieron reuniones periódicas antes de las cumbres del G-20, con objeto de coordinar sus posiciones en el seno de dicho grupo. A finales de mayo de 2009, se realizó en Rusia un primer encuentro entre sus asesores de seguridad nacional, para discutir las implicaciones de la crisis financiera global de 2008. Mientras que el $1^{\circ}$ de septiembre de ese año se realizó, igualmente, el primer encuentro entre las autoridades de competencia del BRIC en Kazán, Rusia (BRIC 2009).

En 2010, se realizó la segunda cumbre de líderes del BRIC en Brasilia, cuyos resultado más importantes fueron una declaración conjunta, un memorándum de cooperación firmado entre los bancos de desarrollo del BRIC -en el caso indio fue su Banco de Exportación e Importación (Eximbank)-, ${ }^{5}$ así como una publicación estadística sobre BRIC. Asimismo, hubo un segundo encuentro entre los asesores de seguridad nacional el 16 de abril en la misma ciudad; mientras que el tercer encuentro fue en octubre, en Sochi, Rusia.

Además, el 26 de marzo de 2010 se realizó el primer encuentro entre los ministros de agricultura de BRIC, en Moscú. Esto muestra igualmente que los países de BRIC van adquiriendo una mayor articulación y coordinación, sin perder su flexibilidad como grupo informal de discusión. Además, la recapitulación anterior sólo da cuenta de algunos encuentros, pues más allá de las reuniones oficiales, también se ha tendido a establecer lazos entre comunidades académicas y empresariales de los cuatro países, en los márgenes de su segunda cumbre; como lo muestra el Foro de Negocios combinado BRIC e IBS, el encuentro de bancos de desarrollo, el Foro de Cooperativas y un Foro Académico BRIC (BRIC, 2010).

Así, el 14 de abril de 2011 tuvo lugar la tercera cumbre de líderes en Sanya, China, con el lema "Visión amplia y prosperidad compartida" y su agenda se centró en cuatro subtemas: la discusión general de la situación internacional actual, los asuntos económicos y financieros internacionales, los asuntos del desarrollo internacional y la cooperación entre los países del BRICS, cuyo resultado principal fue la entrada de la República de Sudáfrica a dicho grupo.

También es importante señalar que, en la declaración final, India obtuvo el apoyo de Brasil, Rusia, Sudáfrica y China para su ingreso como miembro permanente del

\footnotetext{
${ }^{5}$ El Eximbank de India es el órgano ejecutor de la cooperación con otros países, centrado en la dotación de créditos blandos, tanto para la exportación de productos indios como para su adquisición fuera del subcontinente.
} 
Consejo de Seguridad de la ONU. Paralelamente a dicho encuentro, se reunieron los ministros de comercio, los directores de los bancos de desarrollo y los asesores en seguridad nacional; de igual manera, se llevó a cabo el segundo Foro de Negocios del BRICS, durante el cual se signó un memárandum de entendimiento para establecer puntos permanentes de contacto en dicho foro. Al mismo tiempo, se firmó el Acuerdo Marco para la Cooperación Financiera dentro del Mecanismo Interbancario de Cooperación del BRICS, para ampliar las líneas de crédito en divisas locales. También se reeditó la publicación estadística de BRICS, incluyendo al nuevo miembro Sudáfrica.

Otro resultado relevante fue el Plan de Acción, el cual cuenta con tres capítulos o partes y un total de 23 puntos. Dicho plan toca temas como el de seguridad, finanzas, vínculos empresariales, agricultura, salud, cultura, deportes, ciencia y tecnología, y economía verde. Este grupo también deja ver que, hasta cierto punto, busca ampliar las áreas de cooperación y coordinación. De hecho, se transita de una agenda económica y financiera a una más ligada al medio ambiente y la salud, aunque sin descuidar los temas antes desarrollados (BRICS, 2011).

En ese sentido, la reunión de ministros de salud del 11 de julio de 2011, la segunda de ministros de agricultura para el establecimiento de un sistema de información agrícola del mismo año, la de líderes de instituciones estadísticas de septiembre de 2011, la segunda Conferencia de Competencia Internacional (en esas mismas fechas) y la posibilidad de la firma del Acuerdo de Cooperación entre Agencias Antimonopolio, parecen mostrar cómo BRICs buscan consolidar este grupo y, al parecer, transformarlo en algún tipo de mecanismo de cooperación que parecería perder cierta flexibilidad, pero que sigue dando márgenes de maniobra para establecer políticas individuales (BRICS, 2011).

A finales de marzo de 2012, como resultado de la cumbre de líderes realizada en la capital india, BRICs redactaron la Declaración de Delhi, cuyo título fue "La alianza BRICs por la estabilidad, la seguridad y la prosperidad globales", la cual trató una serie de temas y preocupaciones comunes: económicos, financieros, institucionales, así como de seguridad alimentaria y energética. Y dio lugar a una serie de novedades, por ejemplo, la publicación, por primera vez, del Reporte BRICS, un estudio estadístico de cada país y una breve serie de sugerencias sobre las áreas de oportunidad de cooperación entre los distintos miembros (BRICS, 2012).

Asimismo, se anunció la formación de un grupo de trabajo integrado por los ministros de finanzas de cada país, con objeto de indagar la viabilidad del establecimiento de un banco de desarrollo, cuya misión sería el financiamiento de distintos proyectos de infraestructura y desarrollo sustentable en los BRICS, así como en otras economías emergentes y países subdesarrollados, como complemento al actual entramado de instituciones financieras regionales y globales de desarrollo. De igual manera, se concretó 
el Acuerdo Maestro sobre la Disponibilidad de Extensiones de Crédito en moneda local, bajo el Mecanismo de Cooperación Interbancaria de BRICs y el Acuerdo Multilateral para la Disponibilidad de Cartas de Crédito entre los bancos de Exportación e Importación y Desarrollo. Al mismo tiempo, se establece el Plan de Acción de Delhi, cuyos diecisiete puntos enmarcan la coordinación de BRICs en las instituciones multilaterales más importantes en los ámbitos de las finanzas y el comercio globales, y en el seno de la ONU. Por último, se señala la necesidad de explorar áreas de cooperación en energía, evaluación académica y estrategia futura a largo plazo, el Diálogo en Políticas hacia la Juventud y cooperación en asuntos relacionados con la población (BRICS, 2012a).

En marzo de 2013, se realizó la cumbre de Durban, Sudáfrica, cuyo título fue “El BRICS y África: una alianza para el desarrollo, la integración y la industrialización", mostrando cómo el continente africano llama la atención de este grupo de países, teniendo como puerta de entrada al miembro anfitrión. De hecho, en el marco de la cumbre se llevó a cabo el Foro de Diálogo de Líderes BRICS-África, cuyo tema fue "Liberando el potencial de África: la cooperación en infraestructura del BRICs y África", con la presencia de los presidentes de la Unión Africana (UA) y de la Comisión de la UA, al igual que líderes africanos representantes de las ocho comunidades económicas regionales africanas y la Iniciativa Presidencial para el Fomento de la Infraestructura de la Nueva Alianza para el Desarrollo de África (NEPAD, por sus siglas en inglés).

Entre los resultados más importantes, destacan la conclusión del Acuerdo Multilateral sobre Cooperación y Cofinanciamiento para el Desarrollo Sustentable entre los bancos de desarrollo y de exportación e importación del BRICs y el Acuerdo Multilateral sobre Cofinanciamiento de Infraestructura por África; al igual que el anuncio de los ministros de finanzas sobre el establecimiento del nuevo banco de desarrollo, previamente mencionado en Delhi, el cual también financiará proyectos de desarrollo sustentable en África, aunque no se ha hablado de una fecha concreta para su apertura o los montos de su capital; junto a esto, se mencionó que la conclusión de los ministros de finanzas y gobernadores de los bancos centrales fue que el Acuerdo de Reserva Contingente (ARC) entre los países de BRICs tendría un efecto preventivo, lo cual ayudaría frente a las presiones de liquidez de corto plazo y a la estabilidad financiera, sin mencionar que complementaría los acuerdos internacionales como una línea adicional de defensa. Dicho acuerdo sería concomitante al nuevo banco de desarrollo y tendría un tamaño inicial de cien mil millones de dólares (BRICS, 2013). Durante la reunión del G-20 en San Petersburgo, el 13 de septiembre de 2013, se dio a conocer que el nuevo banco tendrá un capital de 50000000000 de dólares, aunque no la distribución de las contribuciones entre BRICS, empero la del ARC se estableció de la siguiente manera: China 41000000000 de dólares, Brasil, India y Rusia 18000000000 cada uno y Sudáfrica 5000000000 (BRICS, 2013). 
Sin embargo, esta cumbre también fue una oportunidad para reafirmar y consolidar el discurso establecido en las cumbres previas, como lo prueba el objetivo explícitamente expuesto en el numeral segundo de la Declaración de eThekwini: "llevar progresivamente a BRICs hacia un mecanismo maduro de coordinación efectiva y de largo plazo en un amplio rango de temas claves relacionados con la economía y la política mundiales" (BRICS, 2013), meta que no se había visto tan claramente descrita en otras declaraciones y que muestra un punto de mayor compromiso entre las partes a nivel discursivo.

De hecho, la ampliación de la agenda de BRICs ha sido útil, en gran medida, para este propósito, contando con la ayuda de los demás miembros y las preocupaciones comunes que afectan a éstos y a India. Dichos temas han servido a Nueva Delhi para promover su propia agenda en dos frentes: 1) el impulso de iniciativas o temas importantes para India en distintos foros y 2) la reforma de ciertos organismos internacionales, con un muy especial interés en la ampliación del Consejo de Seguridad de la ONU, así como la obtención de un lugar como miembro permanente. En este sentido, para analizar cómo India se mueve en estos dos frentes, es necesario estudiarla en esta lógica, haciendo énfasis en los temas que más interesan al subcontinente, para después explicar las razones que condujeron a India a formar parte del BRICs e impulsar su activismo internacional a través de este grupo.

\section{TERRORISMO INTERNACIONAL}

Cuando se habla de terrorismo internacional, India tiene muy en claro a qué tipo de organizaciones terroristas se refiere. Si bien desde su independencia Nueva Delhi ha tenido que cargar con una pesada herencia de violencia sectaria, reivindicaciones fronterizas y el colonialismo, la variable paquistaní ha sido la más importante y duradera. De hecho, el conflicto territorial en la provincia de Jammu y Cachemira sigue latente. De ahí que haya grupos jihadistas paquistaníes reivindicando el territorio cachemir y denostando la presunta opresión que sufren los musulmanes indios. Dichos grupos han perpetrado varios atentados durante los últimos veinte años, como la serie de trece bombas que azotaron el corazón financiero de India, Mumbai, en 1993. Estos ataques han sido adjudicados principalmente a dos grupos islamistas, Lashkar-e-Taiba y Jaish-e-Mohammed, a quienes se les liga con el IsI paquistaní, por lo cual el proceso de paz en la región ha sufrido varios reveses y titubeos (Sur, 2005: 14-17). ${ }^{6}$

\footnotetext{
${ }^{6}$ De particular severidad fueron los atentados del $1^{\circ}$ de octubre en la Asamblea Legislativa de Jammu y Cachemira y del 13 de diciembre de 2001 en el Parlamento federal en Nueva Delhi; sobre todo por el consecuente rompimiento de las relaciones diplomáticas indo-paquistaníes. En 2003, el proceso de paz se restablece, al igual que las relaciones entre Islamabad y Nueva Delhi y hacia 2005 el presidente paquistaní Pervez Musharraf declara en la India que dicho proceso es irreversible. Sin embargo, acontecimientos como el
} 
El 14 de julio de 2011, se registró una serie de tres explosiones simultáneas en Mumbai, que comenzaron una paranoia gubernamental que derivó en la puesta en alarma de todo el territorio indio. Por un lado, los medios y el gobierno indio culparon a los jihadistas paquistaníes, primordialmente al ISI, así como al gobierno de Islamabad por no haber ejercido medidas más efectivas contra estos grupos y establecer una cooperación mayor en la captura de los perpetradores de los atentados. Por el otro, trece días después, el 27 de julio del mismo año, la recién nombrada canciller paquistaní, Hina Rabbani Khar, visitó Nueva Delhi, con el objetivo de continuar y volver a impulsar las conversaciones sobre paz y cooperación. En otras palabras, aún queda voluntad política para destrabar el proceso de paz, por parte de las dos partes, pero también hay muchos obstáculos y el terrorismo se halla dentro de las prioridades de la seguridad nacional india.

Es aquí cuando el BRICs adquiere cierta relevancia, pues el terrorismo es un punto en común con Rusia y China, países que experimentan situaciones parecidas a India en los territorios de Osetia del Norte, Ingusetia, Daguestán, Chechenia o Xinjiang. De igual manera, este asunto tiene la ventaja de servir de puente con Estados Unidos, al estrechar los lazos con éste y su guerra contra el terrorismo internacional. Lo que dota a estos países de un margen de maniobra en las medidas para luchar contra este problema, lo cual Washington no podrá criticar o, en su defecto, apoyará.

De hecho, a India le interesa mucho que Estados Unidos la apoye en su lucha contra los jihadistas paquistaníes, ya que aquél, desde su incursión bélica en Afganistán, ha establecido un acercamiento importante con Pakistán. Con lo cual la presión que Washington ejerza sobre Islamabad será bien recibida por Nueva Delhi, sin mencionar la cooperación en inteligencia que permita prevenir los atentados en territorio indio. No es gratuito que las autoridades indias hayan establecido un acercamiento al régimen de Kabul, sobre todo por los movimientos que llegue a realizar el Talibán paquistaní en contra de India (Barbier, 2011).

En el caso de Brasil y Sudáfrica, si bien son países que no padecen el problema del terrorismo, para tener un cierto margen de maniobra frente a la política de seguridad de Estados Unidos, son sensibles a esta problemática internacional y aceptan su discusión. Sin olvidar que India tiene una importante actuación en la negociación de un borrador de la Convención Integral contra el Terrorismo Internacional, respaldada por Rusia, con un grupo de trabajo conjunto sobre este asunto desde 2006 (Ministry

asesinato en 2007 de la ex primera ministra Benazir Buttho -y candidata favorita en las elecciones generales paquistaníes de 2008-, la situación política de Pakistán después de la salida de Musharraf del poder en 2008; los constantes connatos de violencia en la región del Valle del Swat -limítrofe con Afganistán- y la situación de inestabilidad en el territorio afgano, entre otros factores, restringieron el proceso de paz, a pesar de los avances que se fueron dando en la segunda mitad de la primera década del siglo XXI. 
of External Affairs, 2011: xii, 103, 115-116 y 125-126); así como el apoyo de los demás miembros del BRICS, de acuerdo con lo señalado en la Declaración de Sanya (India Today, 2011b).

\section{ARMAS DE DESTRUCCIÓN MASIVA}

En el caso del debate internacional sobre las armas de destrucción masiva, su relación con el terrorismo internacional inquieta a los líderes indios en Nueva Delhi; es decir, el hecho de que algún grupo terrorista adquiera armas de este tipo es lo que preocuparía a India. De ahí que haya presentado en 2009, en el seno del Primer Comité de la Asamblea de la ONU, tres resoluciones al respecto: 1) medidas para evitar la adquisición de armas de destrucción masiva por terroristas, 2) Convención sobre la Prohibición del Uso de Armas Nucleares y 3) reducción del Peligro Nuclear. Las tres resoluciones tuvieron una buena acogida en la ONU, pero la primera fue la más importante, al haberse adoptado por unanimidad.

De igual forma, hubo una actuación constructiva en la Comisión de Desarme de la ONU, ya sea respecto de las armas biológicas, químicas, ciertas armas convencionales, así como armas pequeñas y ligeras (Ministry of External Affairs, 2010: xiv, 30 y 127-130). En el seno de BRICS, a India le interesa sobre todo la ya mencionada vinculación con el terrorismo internacional, teniendo una política de desarme ad hoc a sus intereses, pues Nueva Delhi tiene capacidad nuclear desde 1974 y una estrecha cooperación con fines pacíficos con Estados Unidos desde 2005, mediante un acuerdo de cooperación nuclear para uso pacífico.

Asimismo, cabe destacar que India es un productor de armas, si bien no el más importante, sí uno que está dispuesto establecer esquemas de cooperación militar y de seguridad con regímenes autoritarios, como el de la Junta Militar de Myanmar o el de Nepal (Sur, 2005: 63 y 64). Sin mencionar la importante cooperación militar que mantiene con Rusia en el desarrollo de los misiles cruceros supersónicos BrahMo, así, el 12 de agosto de 2011 se probó exitosamente la versión Block-III de los misiles cruceros supersónicos BrahMo, de los cuales ya se ha producido una versión Block-III (PTI, 2011), así como las sustanciales compras de armamento a Israel, su segundo proveedor en 2005 (Sur, 2005: 24-27).

Sin embargo, la capacidad nuclear del vecino Pakistán y la posible adquisición de este tipo de armamento por parte de grupos terroristas que le son hostiles pone en alerta a los líderes de India, por lo cual la cooperación con China -cuyas relaciones con Pakistán son muy cercanas por la antigua rivalidad que compartían frente a India- es de capital importancia. No obstante, este tipo de temas no ha tenido tanto eco 
en los BRICS, como el de terrorismo internacional, pues en las declaraciones de Ekaterimburgo, Brasilia y Sanya no hay una clara mención al respecto, pero sí al compromiso para que "BRICS y otros países emergentes desempeñen un papel más importante en la contribución a la paz mundial, seguridad y estabilidad, impulso al crecimiento económico mundial [...], al multilateralismo y promoción de una democracia más amplia en las relaciones internacionales" (BRICS, 2011).

\section{Cambio climátıco}

Éste es uno de los temas que, desde 2010, en Brasilia, parece haber atraído la atención del BRICS, sobre todo por el impulso de su posición negociadora en reuniones como la cop16 en Cancún, México; pero particularmente en la cop17, cuya sede fue Durban, Sudáfrica, del 28 de noviembre al 9 de diciembre de 2011. Asimismo, es menester mencionar que India es parte del grupo Basic, ${ }^{7}$ compuesto por China, Brasil y Sudáfrica, los cuales en su conjunto presentan una posición especialmente contraria a los países más industrializados y contaminantes, pues consideran injusto que estos últimos traten de limitar su ritmo de crecimiento económico, mientras que dichos países desarrollados no tuvieron las mismas restricciones durante sus procesos de industrialización, por lo cual los compromisos para la reducción de las emisiones de carbono no encuentran un consenso para la aplicación del Plan de Acción de Bali o del Acuerdo de Copenhague, sin mencionar que en 2010, en Cancún, tampoco se llegó a algún tipo de convenio que sustituyera o prolongara las disposiciones del Protocolo de Kioto.

Lo anterior delinea la vinculación entre el cambio climático y la seguridad energética, la cual se origina en las perturbaciones que las emisiones de gases de efecto invernadero -derivadas de los procesos productivos-industriales, energéticos y de transporte- de los distintos países provocan respecto del aumento en las temperaturas del orbe, lo cual, a su vez, genera un incremento en la potencia de ciertos fenómenos naturales como ciclones, sequías, inundaciones, etc., cuyas afectaciones son de tipo humano o material, además de hambrunas y epidemias.

En esencia, el discurso del gobierno de India centra la discusión en el hecho de que "más del 50 por ciento de dichas emisiones provienen de los países miembros

\footnotetext{
${ }^{7}$ El único país del BRIcs que no es miembro del Basic es Rusia, lo cual evidenciaría una cierta división en el grupo, sin embargo, Moscú parece no tener problemas en acercarse a la posición de los demás miembros, al menos desde 2009, año en que se llevó a cabo la 9a Reunión Trilateral India-Rusia-China de Ministros de Relaciones Exteriores en Bengaluru, donde se intercambiaron visiones sobre el cambio climático, entre otros temas.
} 
de la OCDE, mientras que India, con el 17 por ciento de la población mundial, sólo contribuye con el 4 por ciento de éstas; asimismo, el calentamiento global fue causado por el importante volumen, continuo y acumulado, de las emisiones de los países industrializados, pero sus efectos serán resentidos por los países en vías de desarro1lo, por lo cual es urgente un compromiso para una importante reducción de los gases de efecto invernadero, por parte de los primeros, y el cambio en los patrones de producción y consumo, sin embargo, el problema son los verdaderos emisores que quieren mantener el espacio del carbón mundial para su desarrollo" (Bhasin, 2009: 131). Es decir, India quiere -junto con los demás países del BRICs- garantizar su seguridad energética, al mismo tiempo que su espacio de carbono, con objeto de impulsar y mantener su desarrollo, y que los países más contaminantes reduzcan sus correspondientes espacios de carbono, en reciprocidad por las emisiones que realizaron durante sus procesos de industrialización y desarrollo.

Pese a esto, India también es consciente de la necesidad de medidas para la mitigación de los efectos de estas emisiones y del empleo de tecnologías más limpias. De hecho, en 2008, Nueva Delhi estableció un Plan de Acción Nacional en Cambio Climático y en palabras del premier Singh: "Sin una cuidadosa estrategia a largo plazo, el cambio climático puede minar nuestros esfuerzos por desarrollarnos, con consecuencias adversas, en general, para el sustento de nuestro pueblo [...], su salud y bienestar" (Bhasin, 2009: LXIII-LXVI).

Por lo cual, India ha establecido este tema como uno de los retos clave que tienen dimensiones globales y que requieren una acción cooperativa global para enfrentarlos efectivamente, de tal manera que en varios foros y reuniones de alto nivel instituye dos imperativos en su política exterior: preservar del espacio para el desarrollo de India y mejorar la seguridad energética; conjuntamente, en su discurso expresa el deseo de que los compromisos entre los países desarrollados y los que están en desarrollo sean equitativos (Ministry of External Affairs, 2010: xiv, 132, 145).

Así, el grupo Basic se ha coordinado para impulsar puntos en común dentro de esta agenda, como lo muestran las reuniones que tuvieron en Nueva Delhi (en enero), Ciudad del Cabo (en abril), Río de Janeiro (julio) y Tianjin (octubre), antes de la cop16 en Cancún en 2010. No obstante, para la cop17 parece que la estrategia cambió un poco, pues no hubo reuniones preparatorias como en 2010. Aunque los canales de comunicación parecen ser más fluidos, pues en la cumbre de Sanya el planteamiento fue muy claro: “el apoyo a los acuerdos llegados en Cancún, llevar la cop17 a una conclusión exitosa e impulsar la cooperación práctica en la adaptación de sus economías y sus sociedades al cambio climático" (BRICs, 2011).

Asimismo, este tema también se desahogó en las reuniones del IBS, por lo cual las posiciones serían mejor coordinadas, lo cual les permite un contacto y consulta 
permanente sobre este asunto. De igual forma, del 4 al 6 de junio de 2012, se celebró la Conferencia sobre Desarrollo Sostenible en Brasil, la cual también fue una plataforma para establecer el plan de trabajo y la posición de los demás miembros de BRICS en el debate sobre el desarrollo, medio ambiente y sostenibilidad.

\section{SEGURIDAD ENERGÉtICA Y ALIMENTARIA}

Los diversos temas de la agenda de BRICs que se analizan en este apartado están vinculados estrechamente, pero para fines prácticos del análisis se estudian separadamente. En el caso de la seguridad energética y alimentaria no es diferente. Así, estas iniciativas van más dirigidas a consolidar una posición coordinada frente a los países más desarrollados del orbe en las distintas mesas de negociación, como la Organización de Naciones Unidas para la Alimentación y la Agricultura (FAO, por sus siglas en inglés), o la OMC, además de fortalecer la cooperación en estos rubros entre los países de BRICS.

De tal manera que, en el caso de la seguridad energética, cabe observar que la diversificación es una estrategia común entre los miembros del grupo, ya que la mayoría necesita de suficientes suministros de energía para mantener sus elevados ritmos de crecimiento o para reimpulsarlos, como en el caso de Sudáfrica. Pese a ello, se observa una importante diferencia en la definición de la seguridad energética de los cinco países, ya que, por un lado, Rusia y Brasil son dos importantes productores de petróleo y gas, pues de acuerdo con datos de la Agencia Internacional de Energía (IEA, por sus siglas en inglés), en 2011, el primero produjo $514864000 \mathrm{TEP}^{8}$ de petróleo crudo y 552728000 TEP de gas natural, y su producción total, calculando todas sus fuentes de energía, fue de 1314875000 TEP, mientras que su consumo total final fue de 458571000 000, lo cual deja ver que sus necesidades energéticas fueron ampliamente satisfechas; en el caso del segundo, produjo 112833000 TEP de petróleo crudo, 78405000 TEP en biocombustibles, y su producción total fue de 249201000 TEP y su consumo total final fue de 217889000 TEP, con lo cual se advierte que también satisface sus necesidades energéticas, aunque importa más de lo que exporta (IEA, 2011; OMC, 2012: 29, 141).

Por otra parte, India y China son dos importantes consumidores de energéticos, la primera tiene una producción menor de petróleo crudo, al igual que de gas natural,

\footnotetext{
${ }^{8}$ TEP significa "toneladas de equivalente de petróleo", una unidad de medida de energía utilizada por la IEA y la Organización para la Cooperación y Desarrollo Económicos (OCDE), que equivale aproximadamente a la energía desprendida de una tonelada de petróleo, 41868000 de julios u 11630 kilovatios/hora.
} 
pero mantiene una importante producción de energía a partir del carbón a nivel mundial, 252166000 TEP -de hecho, en 2002, el 53.9 por ciento de consumo energético indio fue satisfecho por el carbón, el 36.1 por ciento por el petróleo y el 7 por ciento por el gas, según las proyecciones de la IEA, en 2030 la proporción será el 47.2 por ciento por carbón, el 34.9 por ciento por crudo y el 11.7 por ciento gas, lo que explica por qué India busca el acceso al petróleo, gas y otras fuentes de energía en otras partes del mundo-.

Pese a lo anterior, su consumo energético aumenta vertiginosamente, en 2002, su consumo total fue de 330 millones de TEP, en 2011 fue de 492513000 TEP y en 2030 se proyecta en 768000000 TEP, sin mencionar que, en 2011, el 39.6 por ciento de sus importaciones fueron combustibles y productos mineros, lo que deja ver las apremiantes necesidades energéticas de India.

En el caso de China, en 2011 produjo 1823391000 de TEP de carbón, su fuente más importante, 203031000 TEP de petróleo crudo -aunque importó 253779000 TEP-, y 216423000 TEP de biocombustibles, su tercera fuente de energía, mientras que su consumo total fue de 1634706000 TEP.

Lo anterior hace pensar que sus necesidades energéticas estuvieron completamente satisfechas a través de su producción carbonífera, sin embargo, ésta no es la fuente de energía más eficiente. Asimismo, la economía china importó una cantidad importante de carbón, más petróleo del que produce, productos petroleros y gas natural; no obstante que también realiza exportaciones, sin obviar el hecho de que el 29.6 por ciento de sus importaciones fueron combustibles y productos mineros en 2011, el segundo rubro en importancia detrás de las manufacturas (IEA, 2011; OMC, 2012: 41, 84).

En el caso de Sudáfrica, la mayor fuente energética que produjo el país en 2011 fue el carbón y la turba con 142745000 TEP, la segunda fueron los biocombustibles, con 14799000 TEP, mientras que su producción total fue de 162577000 TEP y su consumo total final de 71127000 TEP, con lo cual se aprecia que Pretoria no tiene problemas de seguridad energética en el corto plazo, sin embargo, a pesar de exportar más de lo que importa, hay un fuerte gasto en la importación de petróleo crudo, productos petroleros, gas natural y electricidad, por lo que no sorprende que el 23.6 por ciento de sus importaciones sea en el rubro de combustibles, por lo cual la economía sudafricana encara una serie de retos, entre los que destaca asegurar el suministro de energía para una economía que busca crecer a un ritmo mayor, además de evitar las perturbaciones que provoca el precio del crudo, aspecto que comparte con los demás miembros del BRICS (IEA, 2011; OMC, 2012: 157).

Los datos anteriores dejan ver que hay puntos en común entre India, China y Sudáfrica -aunque también de fricción entre los dos primeros por su competencia-, y entre éstos y Rusia y Brasil. En tal caso, China e India tienen inversiones, participación y concesiones de explotación en campos petroleros rusos y brasileños -de parte de 
India están los bloques Sajalín-I, 69, 70-1, 70-2, 70-3, 77, 80, 85-1, 85-2 y 86 en Rusia y BC-10, вM-Seal-4, BM-BAR-1, BM-ES-42, BM-S-73 y S-74 en Brasil (ONGC Videsh, 2011). Sin embargo, las mayores fuentes de petróleo de los dos gigantes asiáticos provienen de Medio Oriente y África, al mismo tiempo, Sudáfrica no produce, sino que más bien importa, petróleo crudo (OMC, 2012: 157).

Por lo cual, la diversificación de las fuentes de energía es un asunto que atañe a cada uno de los miembros de BRICS, al ser parte importante de su particular estrategia de seguridad energética, sobre todo teniendo en cuenta los vaivenes de los precios del crudo y el gas -y su relación con el aumento de la inflación-, así como de la competencia entre las potencias económicas más importantes, como Estados Unidos y la UE, y éstos y las potencias emergentes como BRICs, incluso entre sí mismos, por el aseguramiento del acceso a los recursos energéticos en todo el orbe.

De igual modo, en todas las declaraciones de BRICs se habla de seguridad energética, pero aún no se establecen mecanismos más articulados para dirigir, institucionalizar o administrar la cooperación en este rubro.

Así, conforme a lo antes expuesto, se advierte cómo la seguridad energética representa una de las prioridades más importantes para la política exterior de India. Resulta ilustrativo observar que la seguridad energética es en los informes anuales del Ministerio de Relaciones Exteriores uno de los rubros a tratar, sin mencionar que dentro de dicha dependencia gubernamental desde 2007 existe una unidad dedicada a este rubro, y en 2009 se transformó en una división completa, cuya misión es "hacer aportaciones para articular la posición de la India en los asuntos de seguridad energética en varios foros multilaterales" (Ministry of External Affairs, 2010: 132, 145) como BRICs, la Asamblea General de la ONU, el G-20, el Movimiento de los No Alineados, los Encuentros Asia-Europa (ASEM, por sus siglas en inglés), IBS, los encuentros de ministros de Energía del Este de Asia, la Conferencia sobre Medidas de Interacción y Construcción de Confianza en Asia (CicA, por sus siglas en inglés), la Mancomunidad Británica de Naciones, entre otros; tarea que realiza en coordinación con otras agencias gubernamentales y grupos de trabajo. En consecuencia, en 2010 se amplió el mandato de esta división a seguridad alimentaria y de los recursos (Ministry of External Affairs, 2011: 136). Esto expone la forma en que Nueva Delhi busca mantener vinculada y coordinada su posición en las dimensiones energética, alimentaria y medioambiental de la seguridad; conjuntamente subraya el hecho de que el grupo BRICs se vuelve un escenario amigable y flexible para su impulso y tratamiento.

Ahora bien, en el caso de la seguridad alimentaria, el interés es compartido por los cinco miembros en los siguientes aspectos: el acceso de sus poblaciones a volúmenes suficientes de alimentos, los precios estables de éstos y la aceptación de una disminución asimétrica de los subsidios agrícolas entre los países en vías de desarrollo 
y los países desarrollados (Sur, 2005: 34). Los casos de China e India son especialmente ilustrativos, pues la lucha que han librado ante las hambrunas es longeva, sin mencionar que una parte trascendente de sus programas de desarrollo se ha enfocado al rubro agrícola, desde el inicio de sus respectivos gobiernos modernos, motivado por poblaciones con un crecimiento igualmente sustancial.

Particularmente en el caso de BRICS, de acuerdo con la FAO, entre el 5 y el 15 por ciento de la población china y brasileña está desnutrida, en los casos ruso y sudafricano, menos del 5 por ciento y entre el 15 y el 25 por ciento de los habitantes de India (FAO, 2012: 71). Si bien Rusia y Sudáfrica parecen ser los países con la mejor situación, también se debe considerar que sus poblaciones, 142000000 y 50000 000, respectivamente, son mucho menos extensas que las de China e India, incluso la de Brasil (de 191000 000) no es comparable (BRICs, 2010), sin embargo, Moscú, Pretoria y Brasilia también enfrentan rezagos: por ejemplo, el 31 por ciento de la población brasileña se halla en pobreza, el 51 por ciento en el caso de zonas rurales; en Rusia, es el 11.2 por ciento, mientras que en Sudáfrica el 26.3 por ciento vive por debajo de la línea de pobreza alimentaria (IFAD, 2013; Interfax, 2013; Statistics South Africa, 2012).

En el caso específico de India, la seguridad alimentaria es un tema sensible, sobre todo después del trauma que causó la crisis agrícola de 1965-1966, después de la cual se instauró la revolución verde en 1968 -junto con las revoluciones blanca y azul-, la cual busca reducir la vulnerabilidad en la disponibilidad de alimentos y frente a presiones del exterior, ya que fue Estados Unidos el que intentó impulsar la liberalización comercial india, a condición de enviar alimentos para aliviar el hambre en la población del subcontinente (Boillot, 2009: 41). Sin embargo, actualmente India es la cuarta potencia agrícola mundial, la segunda superficie cultivada después de Estados Unidos y la primera irrigada en el mundo, además de ser un importante productor de especias, arroz, leguminosas, té, frutas, caña de azúcar, leche, trigo y sorgo, sin mencionar que tiene la población de ganado vacuno más grande del orbe. Aunado a esto, el 60 por ciento de la superficie india es cultivable, lo que se traduce en 190000000 de hectáreas, frente a las 130000000 de China, sin olvidar que Nueva Delhi ofrece mecanismos de ayuda en el sector agrícola a países de Asia del Sur y de África. A pesar de lo anterior, en el año 2000, el 60 por ciento de la población total india tuvo un déficit nutricional en calorías -la mitad de ésta de tipo rural-, el 50 por ciento en lípidos y el 60 por ciento en proteínas -20 por ciento en zonas urbanas, lo que trasluce una severa deficiencia alimentaria en las ciudades (Boillot, 2009: 41)-; y entre 2010 y 2012, según datos de la FAO, el 17.5 por ciento de la población india estuvo desnutrida (FAO, 2012: 91).

Para Jean-Joseph Boillot esta contradicción es causada por la desigualdad en la distribución de alimentos que genera las condiciones para una desnutrición endémica, 
que empeora la situación de trescientos millones de pobres reconocidos por Nueva Delhi; asimismo, la Revolución verde ha mostrado tener ciertos límites, pues, no obstante sus logros, en algunos cultivos como el algodón o la caña de azúcar, se presentan ciclos productivos erráticos, pudiendo haber registros récord en exportaciones o importaciones, en contextos de crecimiento en el consumo.

De igual manera, los límites en su estrategia se evidencian con el fracaso de su producción de legumbres -estancada desde los años sesenta- en un país con un tercio de su población que es vegetariana estricta, y de oleaginosas, lo que hace crecer la importación de aceite. Por último, Boillot señala dos aspectos importantes del agotamiento del modelo agrícola indio: la disminución de las inversiones públicas desde mediados de los años ochenta, particularmente en la irrigación, además de un significativo problema de agua que se agrava por la presión demográfica y la contaminación química, así como los efectos perversos de un círculo vicioso de subsidios que ha causado el aumento de los costos. Empero, la seguridad alimentaria es una prioridad de la agenda india, como lo muestra la prohibición a la exportación de arroz de 2008, debido a la crisis alimentaria desatada ese año, y el establecimiento de la seguridad alimentaria como uno de los cinco retos de India por parte del primer ministro Singh, sin mencionar que en 2013 se aprobó un nuevo esquema federal de subsidio a la compra de alimentos, emanado de la nueva Ley de Seguridad Alimentaria (Boillot, 2009: 41-44; FAO, 2012: 68-78; Singh, 2012).

Pese a lo anterior, Nueva Delhi reconoce que el reto es mayúsculo: por un lado, en 2007 India se convirtió en un importador neto de alimentos; y por el otro, en 2020 se necesitarán 340000000 de toneladas de granos para satisfacer la demanda interna. De ahí la urgencia por explotar los recursos de los países desarrollados, comenzar una segunda revolución verde, utilizar diferentes herramientas (como la biotecnología, la conservación del agua y las técnicas de recolección de agua de lluvia, entre otras). Asimismo, hay iniciativas como el Banco Regional de Alimentos de la SAARC y la Iniciativa para el Conocimiento Agrícola India-Estados Unidos, las cuales buscan complementar estos esfuerzos, entre otras (Bhasin, 2009: 156). Así, aunado a las reuniones y declaraciones de BRICs sobre el sector agrícola, mencionadas líneas atrás, se estableció el Plan de Acción 2012-2016 para la Cooperación Agrícola de BRICS de 2011, lo cual evidencia cómo la cooperación en seguridad alimentaria es una prioridad para este grupo de países, sobre todo frente a la volatilidad de los precios de las materias primas, entre ellas los alimentos y los energéticos (BRIC, 2009; 2010; BRICS, 2011).

Así pues, la vinculación entre la seguridad energética y la alimentaria tiene su base en dos aspectos: su distribución y su disponibilidad, para el consumo humano e industrial y su precio en el mercado. En este último punto cabe recordar que tanto 
los alimentos como los energéticos determinan el precio y la calidad de vida de una ciudad, una entidad federativa o un Estado, puesto que si se incrementa su importe, también crecerá la inflación y el costo de vivir en uno u otro lugar. Por ello, la inestabilidad en los mercados internacionales de estos productos encarece más la vida en los países de BRICS, según el energético o el alimento, trastornando al mismo tiempo las finanzas de los diversos gobiernos, puesto que, como en el caso de India, hay una política de subsidios en estos productos sensibles.

Finalmente, el último eslabón de la relación seguridad energética-seguridad alimentaria es el desarrollo de combustibles elaborados a través de fuentes vegetales o biocombustibles, cuya producción entraña distintos debates y controversias, ya que utilizar fuentes alimentarias para producir energéticos, mas no para nutrir a una población suscita un dilema: energía o alimento. De ahí que el gobierno de India declaró, conjuntamente con el de Brasil, China, México y Sudáfrica, durante una cumbre del G-8, que "es importante que las políticas públicas para la producción de biocombustibles contribuyan al desarrollo sustentable y al bienestar de las personas más vulnerables y no amenacen la seguridad alimentaria" (Bhasin, 2009: 1049).

\section{LA SITUACIÓN ECONÓMICA Y FINANCIERA INTERNACIONAL}

Desde la cumbre de líderes en Ekaterimburgo, los países miembros del grupo BRIC (actual BRICS) se han interesado en la situación de la economía y el sistema financiero internacionales, pues justamente en 2008 se desencadenó la crisis del mercado crediticio inmobiliario estadunidense, con la bancarrota del banco de inversiones Lehmann Brothers y de otras instituciones crediticias y bancarias, con sus respectivas repercusiones en los sistemas financieros de los demás países industrializados y en vías de desarrollo, sin mencionar las crisis de la deuda soberana de los miembros más endeudados de la Unión Europea, como Grecia, España e Irlanda.

En ese contexto nació el G-20, sin embargo, los países BRICs, también miembros del primero, han establecido una posición clara sobre la crisis financiera y sus repercusiones, no sólo en sus propias economías, sino también en las de las naciones más pobres del mundo. Con lo cual dan un impulso a los compromisos para ayudar a estos países a alcanzar los ODM. Lo que se vería como una plataforma de cooperación con las economías menos desarrolladas del orbe. Al igual que una visibilidad mediática importante, pues el argumento para lo anterior ha sido establecer que el crecimiento de la economía mundial no es una cuestión de solidaridad, sino un asunto de importancia estratégica para la estabilidad económica y política globales (BRIC, 2010). No obstante, también establecen que las mayores economías deben continuar impul- 
sando la coordinación de políticas macroeconómicas y trabajar conjunta y coordinadamente para alcanzar un crecimiento sostenible y equilibrado.

En otras palabras, atribuyen una cierta responsabilidad a las economías más industrializadas para dar los pasos necesarios, con el fin de que la economía mundial crezca con un mayor dinamismo y se reviertan (o al menos se mitiguen) los efectos negativos de la crisis de 2008, pues éstos dejaron una honda huella en Brasil, Rusia y Sudáfrica. Aunque en 2010 se volvió a ver un crecimiento importante, los resultados no fueron del todo halagüeños: de acuerdo con las previsiones del FMI crecerán entre el 4 y el 3 por ciento en los siguientes cinco años, mientras que China e India tuvieron entre el 7.8 y el 9.25 por ciento en el mismo periodo (FMI, 2011). Por ello, la estrategia del grupo BRICs ha sido establecer una mayor coordinación en sus demandas dentro de foros como el G-20, FMI, BM y la OMC (BRICS, 2011). Sin embargo, dicha estrategia dio un giro importante en 2013, cuando se anunció la creación del Banco de Desarrollo de BRICs y del ARC, los cuales conformarían un mecanismo alternativo al BM y al FMI-pilares del sistema Bretton Woods, que aún ilustran la distribución de poder en el sistema internacional heredado de la segunda guerra mundial-, y que delinearía una nueva distribución de poder económico y un desafío a la hegemonía estadunidense (BRICS, 2013), aunque no de oposición abierta a Washington, pues el principal objetivo de esta parte de estas medidas es la contención de las presiones inflacionarias y de desequilibrio en la balanza de pagos, así como la disponibilidad de recursos para proyectos de infraestructura.

\section{REFORMAS INSTITUCIONALES}

Vinculado estrechamente con el rubro anterior, al grupo BRICs le interesa, por un lado, reformar las instituciones de tipo económico-financiero, como el FMI y el BM y, por el otro, las de tipo político, como el Consejo de Seguridad de la ONU. Así, BRICs llama la atención hacia la incongruencia que las estructuras de gobierno de las instituciones financieras internacionales reflejan en la actual realidad internacional, remarcando que dichas instituciones no muestran los cambios que se han llevado a cabo en la economía mundial, sobre todo el peso que tienen las economías emergentes en la escena internacional.

Este punto es medular para India, ya que durante los últimos veinte años ha realizado cambios significativos en sus políticas exterior y económica. Después de experimentar significativos incrementos en sus tasas de crecimiento económico, durante la década de los noventa, estableció un mayor acercamiento a su vecindad, sobre todo teniendo en cuenta el conflicto con Pakistán. Después, fue dirigiéndose más y 
más hacia los países del Sudeste Asiático y del Este de Asia, con el fin de mantener lazos comerciales y políticos más cercanos con las economías de Indonesia, Singapur, Japón, Corea del Sur o Malasia. Y en la primera década del siglo XXI acentuó su acercamiento con África y América Latina, sin descuidar los lazos con Europa, Rusia y China, y consolidar aquéllos con Estados Unidos. Empero, el dinámico crecimiento de su producto interno bruto (PIB) ha dotado a India de un peso económico muy trascendente que las potencias económicas más importantes no han podido soslayar, tanto en la posición de consumidor, como en la de vendedor y destino de inversión.

Es decir, India ha adquirido nuevas capacidades en la proyección de sus intereses en el exterior, fenómeno que también se observa en China y Brasil. Así, con el objetivo de mantener e incrementar dichas capacidades internas del país, se ha desplegado una política exterior más agresiva en lo comercial y en lo político. De esa manera, el activismo internacional indio se ha modificado, buscando nuevos medios y usando otras herramientas, pero con metas muy parecidas. Por ello, el hecho de evidenciar su peso económico y político en la escena internacional es tan importante para su desarrollo interno. Y establecer mayores potestades en el sistema financiero internacional tendrá sus réditos, aunque con ello también devendrán mayores responsabilidades. En ese caso, BRICs y el G-20 parecen las herramientas más útiles, por el momento, por la proyección mediática del primero y por la legitimidad del segundo.

En el primer caso, India, junto con Brasil y Sudáfrica, impulsan su imagen y candidatura para acceder a un asiento permanente en el Consejo de Seguridad de la ONU, como parte de una estrategia más amplia cuyo objetivo es hacer frente al reto de transformar ese peso económico en influencia política a nivel regional e internacional. De ahí que el apoyo de Rusia y China, que sí tienen un asiento permanente, es primordial para tener ciertas perspectivas de éxito, de tal suerte que en 2011, en Sanya, se declaró conjuntamente lo siguiente: "Nosotros reafirmamos la necesidad por una reforma integral de la ONU, incluyendo el Consejo de Seguridad, con la esperanza de hacerlo más efectivo, eficiente y representativo, y así poder enfrentar con mayor éxito los retos de hoy en día. China y Rusia reiteran la importancia que ellos otorgan al estatus de India, Brasil y Sudáfrica en asuntos internacionales, y entienden y apoyan sus aspiraciones para jugar un papel más importante en la ONU" (BRICS, 2011; PTI, 2010a). Lo anterior se interpretó en la prensa como un apoyo abierto a los tres países. Sin embargo, cuando se tenga que ver ese apoyo reflejado en una votación o en un pronunciamiento más claro, será cuando se note la solidez y profundidad de los compromisos en un grupo con una agenda tan flexible y amplia. Esto se debe a que China tiene ciertas reticencias a apoyar a India, ya que mantiene lazos estrechos con Islamabad, además de los conflictos fronterizos previamente mencionados. Asimismo, Pekín tiene una posición de competencia frente a los productos y empresas indias, 
por no hablar de la influencia, en Asia del Sur, Sudeste de Asia, Este de Asia, Asia Central y África.

\section{CONSIDERACIONES FINALES}

India es un país que ha experimentado una serie de cambios antes y después de su independencia en 1947, cambios que han sido progresivos y, en algunos casos, perturbadores y complicados, como la colonización inglesa, la independencia, la inestabilidad política y económica, dos magnicidios, etc. Sin embargo, parece que uno de los objetivos que nunca se cuestionó internamente fue su papel en el escenario internacional, un activismo que le acarreó una importante reputación y reconocimiento internacional. La cuestión es que India es la heredera de varias tradiciones, imperios y reinos, cuyo esplendor pertenece al pasado, aun cuando tiene cierta influencia en los líderes de este país.

No obstante, los últimos cambios en el sistema internacional han permitido una transformación profunda y gradual de la economía, la política y la sociedad indias. Dichos cambios van desde la desaparición de la URSS, hasta la nueva configuración de la economía mundial, sin mencionar la crisis de pagos que vivió en 1991. Empero, esto ha obligado a India a cambiar y remover, eventualmente, ciertos obstáculos e inercias. Al mismo tiempo, se ha dado una ampliación en el margen de maniobra en ciertos espacios de la escena internacional, aunado al incremento de las capacidades económicas y políticas de India. En otras palabras, una dinámica bidireccional que modifica tanto el interior como el exterior del subcontinente. Para Zakaria, el cambio en la esfera externa es tan profundo que incluso se pondría en duda cierto dominio o influencia de Estados Unidos, lo cual marca la apertura de nuevos espacios de poder en el mundo.

Así, la membresía en el grupo BRICs significa una oportunidad para mejorar la imagen india después de la crisis de 2008 (Rosas, 2011), así como una plataforma para impulsar su agenda de política exterior, ya sea su entrada al Consejo de Seguridad de la oNU como miembro permanente, la reforma del sistema Bretton Woods, el comercio agrícola y de servicios en la omc o el fortalecimiento de su capacidad negociadora en otros foros. Es decir, es una de tantas iniciativas que le permite proyectar sus intereses al exterior, a través de los espacios que va dejando la hegemonía estadunidense, la cual no se enfrenta o pone en duda directamente, pero sí se modifica, dependiendo del rubro del que se hable.

¿Pero, por qué ser parte del BRICs, del G-20, de Basic, del CiCA, o de otros muchos foros? Para India, esta diversidad de grupos más bien le ayuda a mantener un perfil 
alto en ciertos temas y bajo en otros, pero particularmente a utilizar cualesquiera de estas trincheras para proyectar sus intereses, dependiendo de la agenda a examinar. Por ejemplo, en el grupo Basic se habla netamente de cambio climático; mientras que en el G-20 se hace lo propio sobre las estrategias para el mejoramiento de los sistemas monetarios, financieros y bancarios del orbe; en tanto que en los BRICs se trazan pautas para una agenda más amplia, pero mucho más visible y publicitada por los medios de comunicación. Como estableció Rong Ying, estratega del China Institute of International Studies en Pekín: "Cada uno tiene su utilidad a la hora de promover los intereses indios y Nueva Delhi intenta emplearlos teniendo esto en mente" (Chaudhuri, 2011).

En ese sentido, es evidente que la cooperación y coordinación con los países del BRICS es importante, pero forma parte de toda una urdimbre de foros que permiten a India proyectar su agenda, mientras se compromete hasta donde su conveniencia le dicta. De hecho, su estrategia para obtener el apoyo de los países con una membresía permanente en el Consejo de Seguridad de la ONU es prueba de ello, pues no sólo ha buscado el respaldo de Rusia y China, sino también de Estados Unidos, Reino Unido y Francia (Rao, 2005). Al mismo tiempo que ha desplegado una serie de mecanismos de cooperación para obtener el apoyo de países africanos y asiáticos, sin descuidar a BRICs y los demás foros (Chaudhury, 2011).

India siempre ha tratado de mantenerse en iniciativas grupales para minimizar sus vulnerabilidades y compensar su falta de capacidades para promover sus intereses en el exterior. Hoy en día estas capacidades se han incrementado, pero sigue promoviendo sus intereses a través de iniciativas grupales, ahora más numerosas y onerosas. Empero, en los inicios del siglo XxI, ya no busca la no alineación, sino una política más pragmática y a la inversa, estableciendo buenas relaciones con las potencias económicas más importantes, y con la militar y política hegemónica. Asimismo, no deja de tener importantes vínculos con potencias regionales como China, Rusia o los Emiratos Árabes Unidos, con organizaciones como la Asociación de Naciones del Sudeste Asiático (Ansea), o con países menos desarrollados que India misma, como los de su vecindad.

Ésa es precisamente la ventaja que BRICs le ofrece, el poder mantener esta política de acercamiento y buenas relaciones con la mayoría de los países que le interesan -ya sea por razones políticas, geopolíticas o geoeconómicas-, y no dar la impresión de que se alinea a un solo polo de poder. Así, BRICs le permite a Nueva Delhi mantener un juego complejo, pero mucho más equilibrado que en la era bipolar, al no tener una postura abiertamente antiestadounidense.

Esencialmente, lo que, por el momento, hace al BRICs un instrumento útil para India es la posibilidad de tener buenas relaciones con Estados Unidos -incluso un 
acuerdo de cooperación nuclear para fines pacíficos-, mientras se conserva la cooperación militar y educativa con Rusia y China, respectivamente; asimismo un diálogo profuso y frecuente con Brasil y Sudáfrica. Sólo el tiempo determinará qué tan acertada es la apuesta india y qué tan eficiente es esta política exterior abierta y pragmática, que se adapta a un zakariano mundo posestadunidense.

\section{FUENTES}

\section{Barbier, Charlie}

2011 Agosto, "L'Inde pourrait se lancer dans la prospection minière en Afghanis$\tan ^{\prime}$, en <http: / / inde.aujourdhuilemonde.com/1\%E2\%80\%99inde-pourraitse-lancer-dans-la-prospection-miniere-en-afghanistan $>$, consultada el 25 de agosto de 2011.

BHASIN, Avtar Sing, ed.

2009 India's Foreign Relations 2008 Documents Part - I, Nueva Delhi, Geetika.

BoIllot, JEAN-JosePH

2009 L'Économie de l'Inde, París, La Découverte.

BRICS

2013 "Fifth BRIcs Summit Declaration and Action Plan" (marzo), en <www.brics5.co. za/fifth-brics-summit-declaration-and-action-plan/>, consultada el 28 de septiembre de 2013.

2012a "Fourth BRICs Summit Delhi Declaration" (marzo), en <www.brics5.co.za/ about-brics/summit-declaration/fourth-summit/>, consultada el 28 de septiembre de 2013.

2012b The BRICS Report, Nueva Delhi, Oxford University Press.

2011 "Leaders Meeting Declaration" (abril), en <http: / / www.hse.ru/en/org/hse/ iori / brics_summit_20110411>, consultada el 27 de agosto de 2011.

2010 "Joint Statement of the BRIC Countries' Leaders" (abril), en <http: / / eng.news. kremlin.ru/ref_notes/5>, consultada el 27 de agosto de 2011.

2009 "Joint Statement of the BRIC Countries' Leaders" (junio), en $<$ http: / / archive. kremlin.ru/eng/text/docs/2009/06/217963.shtml>, consultada el 27 de agosto de 2011 . 


\section{Chaudhury, Dipanjan Roy}

2011 "India Gives \$5-billion Aid to Africa" (mayo), en <http: / indiatoday.intoday. in/ site/ story / pm-announces-five-billion-dollars-aid-for-africa/ 1/139212. html>, consultada el 7 de julio de 2011 .

Chaudhuri, Pramit Pal

2011 "Between-World Nations Caught in Alphabet Soup" (abril), en <http: / www. hindustantimes.com/StoryPage/Print/685413.aspx>, consultada el 7 de julio de 2011.

DiKSHIT, PRASHANT

2008 "India and Russia, Revisiting the Defence Relations", IPCS Special Report, núm. 52, pp. 1-9.

Fondo MONETARIO INTERNACIONAL (FMI)

2011 "World Economic Outlook Database" (abril), en <http:/ / www.imf.org>, consultada el 8 de agosto de 2011.

Food and Agriculture Organization (FAO)

2013 FAO Statistical Yearbook, Roma, FAO.

GANGULY, SuMIT

2003 "International Relations", en Sumit Ganguly y Neil DeVotta (eds.), Understanding Contemporary India, Boulder, Col.,Lynne Rienner, pp. 93-110.

Ganguly, Sumit y Manjeet S. Pardesi

2009 "Explaining Sixty Years of India's Foreign Policy", India Review, vol. 8, núm. 1, pp. 4-19.

INDIA TODAY

2011a "India, China to Restore Defence Co-operation", en < http: / indiatoday.intoday.in/site/ story/india-china-to-restore-defence-co-operation/1/135160. html>, consultada el 5 de agosto de 2011 .

India Today Group Digital (ITGD) Bureau

2011a “BRICs meet: China Backs India's “Aspiration' for un Role” (abril), en <http: / / indiatoday.intoday.in/ site/ story / brics-meet-china-backs-indias-aspirationfor-un-role / 1 135274.html>, consultada el 30 de julio de 2011. 
2011b “BRICs Meet: India Seeks Co-op Over Piracy, Terror" (abril), en < http: / / indiatoday.intoday.in / site / story / brics-meet-india-seeks-co-op-over-piracy-terror / 1/135272.html>, consultado el 5 de agosto de 2011.

Instituto Brasileiro de Geografia e Estatística (ibge)

2010 "Joint Statistical Publication by BRIC Countries", en <http:/ / www.brasemb. ru/uploaded/doc/BRIC_Statistics.pdf >, consultada el 21 de agosto de 2011.

2011b "My Job Will Be Done if Ties With Pakistan Normalise: PM" (abril), en <http:/ / indiatoday.intoday.in/ site/ story / my-job-will-be-done-if-ties-withpakistan-normalise-prime-minister-manmohan-singh/1/135495.html>, consultada el 30 de Julio de 2011.

INTERFAX

2013 "Poverty Rate in Russia Went Down in 2012 Russia's Statistics Agency", en <rbth. ru/news/2013/03/25/poverty_rate_in_russia_went_down_in_2012_-_russias_statistics_agency_24208.html >, consultada el 18 de octubre de 2013.

INTERNATIONAL ENERgy AgENCy (IEA)

2011 "Statistics", en < http: / / www.iea.org/ statistics / >, consultada el 12 de octubre de 2013.

International Fund for Agricultural Development (IFAD)

2013 "Rural Poverty Portal", en <www.ruralpovertyportal.org>, consultada el 12 de octubre de 2013.

Joshi, MANOJ

2011 "Break the Sino-Pak Connection" (abril), en <http: / / indiatoday.intoday.in/ site/story/break-the-sino-pak-connection/1/135279.html>, consultada el 30 de julio de 2011.

Mathews, KaY

2011 "India-Africa Cooperation, A Strategic Vision", Africa Quaterly Indian Journal of African Affairs, vol. 51, núm. 1 (Julio), pp. 36-46.

Ministry of External Affairs

2011 Annual Report 2010-2011, Nueva Delhi, Ministry of External Affairs.

2010 Annual Report 2009-2010, Nueva Delhi, Ministry of External Affairs. 
ONGC VIDESH

2010 "Assets", en <http: / / www.ongcvidesh.com/ Assets.aspx?tab=3>, consultado el 25 de octubre de 2013.

Organización Mundial del Comercio (OMC)

2012 Trade Profiles 2012, Ginebra, wTO.

Press TRUst of India (PTI)

2011 “User Trial of BrahMos Block-III Missile Successful” (agosto), en <http:/ / www.lensonnews.com/lensonnews / 1/59/5182/1/user-trial-of-brahmosblock-iii-missile-successful.html $>$, consultada el 20 de agosto.

2010a “UNSC: Russia, China Support Aspirations of India, Brazil”, en <http: / indiatoday.intoday.in/site/ story/UNSC:+Russia,+China+support+aspirations+ of+India,+Brazil / 1/93182.html>, consultada el 30 de julio de 2011.

2010b "PM Pitches for Close Cooperation among BRIC Nations" (abril), en <http: / / indiatoday.intoday.in/ site/ story / PM+pitches+for+close+cooperation+amo ng+BRIC+nations / 1/93086.html>, consultado el 30 de julio de 2011.

RAO, RAMA

2005 "India Enlists French Support for Security Council Berths", en <http: / www. asiantribune.com/show_news.php?id=15609>, consultado el 5 de agosto de 2011.

Rosas, María CRISTINA

2011 “BRIC, cómo se construye una imagen" (julio), en <http: / www.etcetera.com. $\mathrm{mx} /$ articulo.php? articulo $=8447>$, consultada el 20 de agosto.

Sen, Amiti

2013 "India-Russia Likely to Discuss CECA during Sharma's Visit", en <indiaafricaconnect.in/index.php?param=news/6559>, consultada el 21 de octubre de 2013.

Singh, MANMOHAN

2012 "Five Key Challenges Facing India" (agosto), en <http:/ / www.indiacsr.in/ en>, consultada el 18 de agosto de 2012.

Statistics South Africa

2012 Poverty Profile of South Africa, , Pretoria, Statistics South Africa. 
SUR, SERGE, ed.

2005 "L'Inde grande puissance émergente", Questions Internationales, núm. 15 (septiembre-octubre).

WADE, ROBERT Hunter

2003 "What Strategies Are Viable for Developing Countries Today? The World Trade Organization and the Shrinking of 'Development Space'", Review of International Political Economy, vol. 4, núm. 10, pp.621-644.

WEISS, LINDA

2005 "Global Governance, National Strategies: How Industrialized States Make Room to Move under The wTо", Review of International Political Economy, vol. 5, núm. 12, pp. 723-749.

ZAKARIA, FAREED RAFIQ

2011 The Post-American World: Release 2.0, Nueva York, W.W. Norton. 